\title{
Feasibility and Efficiency of the BEFORE (Better Exercise and Food, Better Recovery) Prehabilitation Program
}

\author{
Thaís T. T. Tweed ${ }^{1, *(D)}$, Misha A. T. Sier ${ }^{1}\left(\mathbb{D}\right.$, Ad A. Van Bodegraven ${ }^{2}$, Noémi C. Van Nie ${ }^{1}$, \\ Walther M. W. H. Sipers ${ }^{3}{ }^{D}$, Evert-Jan G. Boerma ${ }^{1}$ (D) and Jan H. M. B. Stoot ${ }^{1}$ \\ 1 Department of Surgery, Zuyderland Medical Center, Dr. H van der Hoffplein 1, \\ 6162BG Sittard-Geleen, The Netherlands; m.sier@zuyderland.nl (M.A.T.S.); \\ no.visser@zuyderland.nl (N.C.V.N.); e.boerma@zuyderland.nl (E.-J.G.B.); j.stoot@zuyderland.nl (J.H.M.B.S.) \\ 2 Department of Gastroenterology, Zuyderland Medical Center, Dr. H van der Hoffplein 1, \\ 6162BG Sittard-Geleen, The Netherlands; a.vanbodegraven@zuyderland.nl \\ 3 Department of Geriatric Medicine, Zuyderland Medical Center, Dr. H van der Hoffplein 1, \\ 6162BG Sittard-Geleen, The Netherlands; w.sipers@zuyderland.nl \\ * Correspondence: th.tweed@zuyderland.nl; Tel.: +31-6-47596097
}

check for updates

Citation: Tweed, T.T.T.; Sier, M.A.T.; Van Bodegraven, A.A.; Van Nie, N.C.; Sipers, W.M.W.H.; Boerma, E.-J.G.; Stoot, J.H.M.B. Feasibility and Efficiency of the BEFORE (Better Exercise and Food, Better Recovery) Prehabilitation Program. Nutrients 2021, 13, 3493. https://doi.org/ $10.3390 /$ nu13103493

Academic Editor: Misha D. P. Luyer

Received: 17 August 2021

Accepted: 29 September 2021

Published: 2 October 2021

Publisher's Note: MDPI stays neutral with regard to jurisdictional claims in published maps and institutional affiliations.

Copyright: (c) 2021 by the authors. Licensee MDPI, Basel, Switzerland. This article is an open access article distributed under the terms and conditions of the Creative Commons Attribution (CC BY) license (https:// creativecommons.org/licenses/by/ $4.0 /)$.

\begin{abstract}
Prehabilitation has been postulated as an effective preventive intervention to reduce postoperative complications, particularly for elderly patients with a relatively high risk of complications. To date, it remains to be determined whether prehabilitation increases physical capacity and reduces postoperative complications. The aim of this study was to assess the feasibility of a 4-week multimodal prehabilitation program consisting of a personalized, supervised training program and nutritional intervention with daily fresh protein-rich food for colorectal cancer patients aged over 64 years prior to surgery. The primary outcome was the feasibility of this prehabilitation program defined as $\geq 80 \%$ compliance with the exercise training program and nutritional intervention. The secondary outcomes were the organizational feasibility and acceptability of the prehabilitation program. A compliance rate of $\geq 80 \%$ to both the exercise and nutritional intervention was accomplished by 6 patients $(66.7 \%)$. Attendance of $\geq 80 \%$ at all 12 training sessions was achieved by 7 patients $(77.8 \%)$; all patients $(100 \%)$ attended $\geq 80 \%$ of the available training sessions. Overall, compliance with the training was $91.7 \%$. Six patients $(66.7 \%)$ accomplished compliance of $\geq 80 \%$ with the nutritional program. The median protein intake was $1.2(\mathrm{~g} / \mathrm{kg} / \mathrm{d})$. No adverse events occurred. This multimodal prehabilitation program was feasible for the majority of patients.
\end{abstract}

Keywords: prehabilitation; colorectal surgery; multimodal; functional capacity; enhanced recovery after surgery; complications; colorectal cancer; feasibility

\section{Introduction}

Despite optimization of surgical techniques with the introduction of minimally invasive surgery and the improvement of perioperative care with Enhanced Recovery After Surgery (ERAS) programs, postoperative complications after colorectal surgery still occur in approximately one-third of patients undergoing colorectal resection, with the elderly at increased risk [1-3]. Worldwide, colorectal cancer is the third most common cancer and second leading cause of cancer death. Annually, approximately 2 million patients are diagnosed with colorectal cancer, of which the majority occurs in the increasing older adult population [4-7]. Since surgery is the standard curative treatment for colorectal cancer, further reduction of complications is paramount [8]. Recently, interest in reducing complications by enhancing patients' condition prior to surgery is rising. Factors that adversely affect outcomes include co-morbidity, polypharmacy, cognitive impairment, dependency, and frailty, which can be measured using the preoperative comprehensive geriatric assessment (CGA) [9,10]. Frailty is characterized by age-related deviations that lead to decreased energy and muscle strength, weight loss, and sedentary activity levels [11,12]. 
In previous studies it has been suggested that some factors adversely affecting postoperative outcomes may be modified before surgery [13]. Prehabilitation aims to increase physiological reserve in anticipation of adverse effects of surgery and to optimize postoperative recovery, especially in the frail patient population [14-16]. It has been postulated that prehabilitation, including nutritional support or physical exercise training prior to surgery, could be effective in reducing patient frailty and improving outcomes after abdominal surgery [13,15-22].

The beneficial impact of prehabilitation on physical capacity and postoperative outcomes remains inconclusive due to contradictory results, small study samples, and large heterogeneity [13,18-25]. This heterogeneity encompasses variation in the content of the prehabilitation program. Nonetheless, in several studies the effects of multimodal prehabilitation consisting of physical training in combination with nutritional support using oral nutritional supplements (ONS), e.g., Nutridrink ${ }^{\circledR}$ have been explored [26,27]. To our knowledge, no trials have been conducted to determine the effect of a multimodal prehabilitation program for elderly patients prior to elective colorectal resection for malignancies that combined personalized physical exercise training and fresh protein-rich food.

The aim of this study was to explore the feasibility of the BEFORE (Better Exercise and Food, Better Recovery) multimodal prehabilitation program consisting of personalized, ambulatory, hospital based exercise training, and fresh protein-rich food in terms of compliance, organization and acceptance to outline the design of a large, statistically well-powered comparative trial.

\section{Materials and Methods}

\subsection{Study Design}

This prospective feasibility study was conducted in one large Dutch teaching hospital (Zuyderland Medical Center, Sittard-Geleen, The Netherlands). After detection of a colorectal malignancy during endoscopy, patients were assessed for eligibility and were enrolled at the outpatient clinic between November 2019 and March 2020. Data were collected at baseline, during all training sessions, before surgery and at 30-days, and 1-year follow-up.

\subsection{Study Participants}

Patients with a colorectal (pre)malignancy were recruited if they were scheduled for an elective colorectal resection and if they met the following criteria: age $>64$ years, $\mathrm{BMI}<35 \mathrm{~kg} / \mathrm{m}^{2}$, physically and mentally capable of completing the exercise program, the ability to answer questionnaires and the ability to orally consume (calculated) daily nutritional requirements. The exclusion criteria were parenteral nutrition or enteral nutrition via feeding tube in the preoperative phase, a history of or an active inflammatory gastrointestinal disease, a palliative treatment course, previous participation in a multimodality approach study, inability or contraindication to exercise, intellectual disability, complex dietary needs or food allergy.

Ethical approval was obtained from the local Medical Ethics Review Committee Zuyderland: Medisch-Etische Toetsingscommissie Zuyderland (METC Z), (NL70834.096.19) the study was conducted according to the ethical standards of the Helsinki Declaration of 1975. All patients provided written informed consent.

\subsection{Baseline Assessment}

Baseline assessment was performed within one week after enrollment by the Sport and Exercise Physician (SEP) and an in-hospital dietician, prior to the start of the multimodal prehabilitation program. A second assessment was conducted after completion of the BEFORE 4-week multimodal prehabilitation program, prior to surgery.

The initial physical screening included physical examination, rest-electrocardiogram (ECG), rest-spirometry and Cardiopulmonary Exercise Testing (CPET; Quark CPET, Cosmed, Rome, Italy) on a calibrated electronically braked cycle ergometer (Excalibur Sport, Lode B.V., Groningen, the Netherlands). To assess baseline aerobic fitness and to establish per- 
sonalized intensities for the supervised training program, CPET determined heart rate, maximum oxygen uptake $\left(\mathrm{VO}_{2} \max \right)$, ventilatory anaerobic threshold (VAT), respiratory compensation point (RCP), carbon dioxide production, respiratory flow and volume parameters in the breath-by-breath measurements. Muscle strength was measured by testing handgrip strength of the dominant hand in 3 consecutive cycles, of which the mean score was determined. To assess nutritional requirements, the dietician asked participants about their daily food consumption, based on which the current protein and energy intake were estimated. In accordance with the European Society for Clinical Nutrition and Metabolism (ESPEN) guidelines, the required protein intake was set at 1.2 to $1.5 \mathrm{~g}$ protein $/ \mathrm{kg}$ bodyweight [28]. The required energy intake was calculated using the Harris-Benedict formula with an addition of 30\% to correct for the malignant disease [29].

Further descriptive assessment included the Short Nutritional Assessment Questionnaire (SNAQ) [30], the Groningen Frailty Index (GFI) [31], the European Organization for Research and Treatment for Cancer Quality of Life Questionnaire (EORTC QLQC30) [32], and a VAS [33] questionnaire, designed for this study, to evaluate appetite and food experience (see Appendix B).

The reassessment included physical examination, CPET, dietary reassessment and a questionnaire evaluating patients' experience with the multimodal prehabilitation program (see Appendix A).

BEFORE prehabilitation program

The BEFORE prehabilitation program has been specifically developed for this study and consisted of an exercise and nutritional intervention.

\subsection{Exercise Intervention}

During four weeks, between diagnosis and surgery, patients received personalized, supervised (by a specialized physiotherapist) exercise training combined with freshly prepared protein-rich food.

The ambulatory training sessions were organized in the hospital. The program consisted of training sessions of 60 to $75 \mathrm{~min}$, three times a week for four weeks, including strength training followed by aerobic training. Strength training involved six functional upper and lower body push-pull exercises (deadlift, chest press, lateral pull down, leg press, shoulder press and seated row). During the first session, the personal one-repetition maximum (1-RM) of each exercise was determined for further training. Each exercise started with 20 repetitions (60-65\% 1-RM), followed by 2 series with 6 repetitions ( $80-85 \%$ 1-RM). Aerobic training consisted of High Intensity Interval Training (HIIT) on the cycle ergometer with 30-s and 60-s intervals and a 1:3 work-recovery ratio, based on the personal ventilatory thresholds measured with CPET [34,35]. Compliance with the exercise program was determined by means of attendance, the mean duration of participation in the training program and the average achieved training intensity.

During all training sessions, the resistance (in kilograms) of the strength training was reported for each exercise. Similarly, the aerobic function was assessed during each session by measuring maximum heart rate and intensity using the Borg Scale [36].

\subsection{Nutritional Intervention}

Patients received three freshly prepared protein-rich meals (breakfast, lunch, dinner) and three snacks per day provided by Daily Fresh Food Inc. ${ }^{\circledR}$, Geleen, the Netherlands. Daily Fresh Food Inc. ${ }^{\circledR}$ produces and supplies high-quality, safe and fresh food. The European Union has assigned the following numbers to Daily Fresh Food: EG-454-NL, EG923-NL. The nutrients contained the required amount of protein and calories as calculated by the dietician. To meet these requirements, the meals were prepared with additional fresh, protein-rich ingredients (a section of the menu is shown in Appendix C). Patients were not allowed to consume other nutrition. To accurately measure the macronutrient intake, patients were asked to complete a 7-day food diary, to weigh each dish and to take pictures of the meals before and after consumption with a provided Samsung tablet (Samsung 
Electronics Co., Ltd., Yeongtong District, Suwon, Korea). Daily Fresh Food Inc. ${ }^{\circledR}$ provided a list of the nutritional value per meal. The macronutrient intake was calculated based on the measurements and nutritional list; unclear (vague or undistinguishable) pictures were reported as missing data.

\subsection{Outcomes}

The primary study outcome was the feasibility of the BEFORE multimodal prehabilitation program, defined as at least $80 \%$ adherence to the exercise training program and the nutritional intervention.

Secondary outcome measures were the organizational feasibility, the acceptability of the interventions, functional capacity after prehabilitation (determined with CPET measures), and muscle strength (determined with handgrip strength and $1 \mathrm{RM}$ ). Other secondary outcomes were length of hospital stay, postoperative complications, readmission rate, and 30-day and 1-year mortality. Complications were divided into surgical and nonsurgical complications and scored according to the Clavien-Dindo classification $[37,38]$.

The organizational feasibility was determined by calculating the success rate of meal order and delivery, as well as the success rate of organizing the intended supervised exercise training.

The acceptability of the nutritional and the exercise training intervention was measured by evaluating patients' experiences with the nutritional intervention and the exercise training intervention using a questionnaire (see Appendix A). Likewise, we explored the feasibility of measuring food intake, and adjusting nutrition to the needs of patients and personalizing training.

\subsection{Statistical Analysis}

To study the feasibility of this multimodal prehabilitation program, the aim was to include 10 patients. As this is a feasibility study, no sample size or power analysis was performed.

The feasibility of the multimodal prehabilitation program was assessed using descriptive analysis. Continuous variables were presented as mean, median, percentage and frequency with standard deviations (SD). Categorical variables were presented as means, median, percentages, numbers and frequency with standard deviations (SD). The Wilcoxon signed rank test was used to assess change in physical capacity before and after prehabilitation. Data were analyzed with the Statistical Package for the Social Sciences for Windows (version 23.0; IBM, SPSS Inc., Chicago, IL, USA).

\section{Results}

Between the 1st of November 2019 and the 5th of March 2020, a total of 119 patients were assessed for eligibility for participation. On $5 \mathrm{March}$, the inclusion of patients was discontinued prematurely due to the Corona pandemic. Of this initial sample, 30 participants met the inclusion criteria. One patient $(3.0 \%)$ was excluded based on a previous colorectal tumor resection, and $20(66.7 \%)$ patients declined participation. The remaining 9 patients $(30.0 \%)$ consented to participate. A consort diagram for the study is presented below (see Figure 1).

Patient Characteristics

The baseline characteristics of the study participants are shown in Table 1. The median age of the participants was 73.0 (IQR 70.0-76.0), and slightly more participants were male $(n=5,55.6 \%)$. Two patients $(22.2 \%)$ had an ASA score of III. Four $(44.4 \%)$ patients were classified as frail based on a GFI score $\geq 4$. Moreover, one patient $(11.1 \%)$ was classified as having a high nutritional risk. 


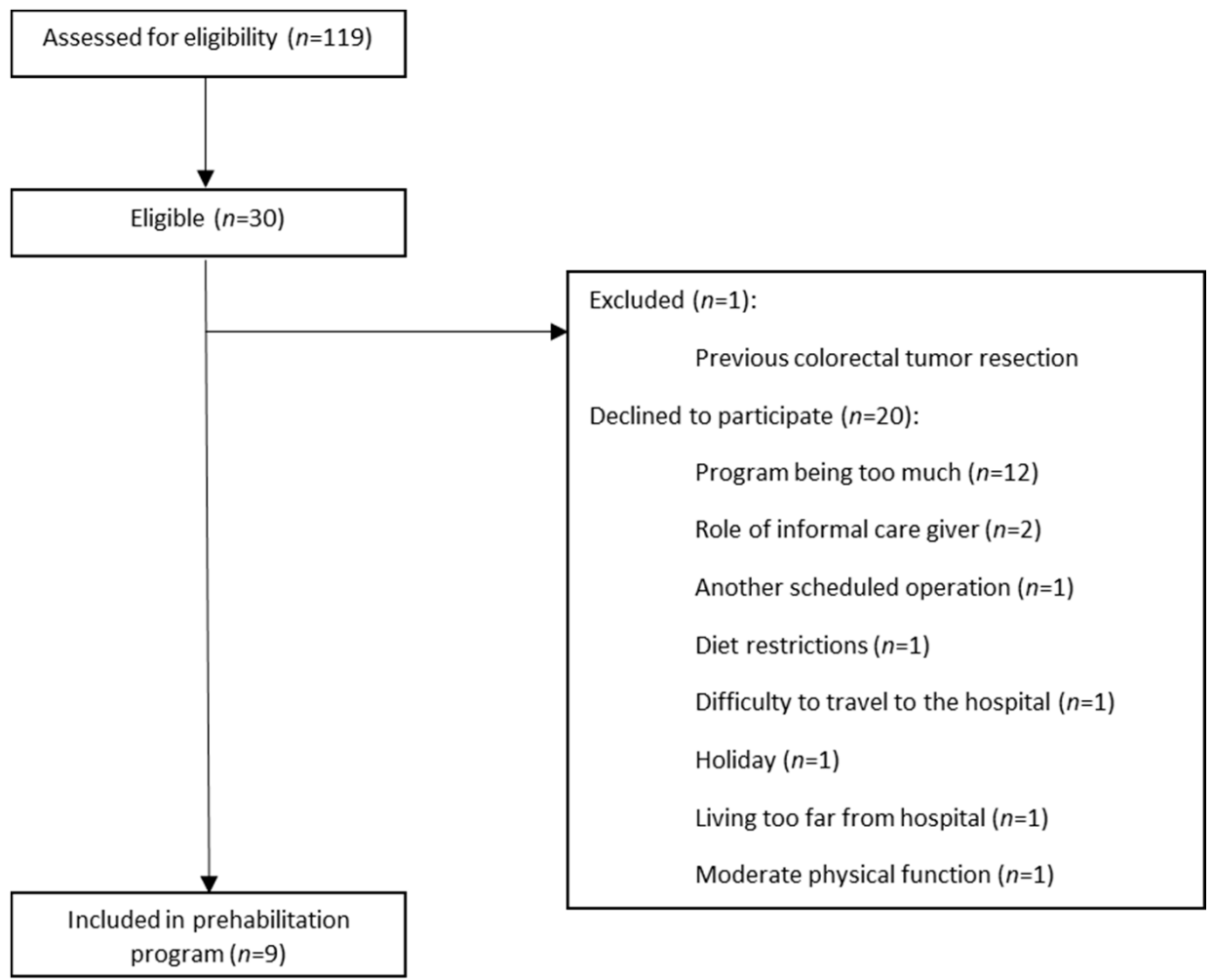

Figure 1. Consort diagram.

Table 1. Descriptive data for patients; median (interquartile range).

\begin{tabular}{|c|c|}
\hline & Study Population $(n=9)$ \\
\hline Age (years) & $73.0(70.0-76.0)$ \\
\hline Gender ratio $(\mathrm{M}: \mathrm{F})$ & $5: 4$ \\
\hline Height (cm) & $169.0(160.5-178.0)$ \\
\hline Bodyweight (kg) & $84.0(73.5-91.4)$ \\
\hline $\mathrm{BMI}^{1}\left(\mathrm{~kg} / \mathrm{m}^{2}\right)$ & $26.9(25.0-32.7)$ \\
\hline Smoking; $n(\%)$ & $1(11.1)$ \\
\hline Alcohol; $n(\%)$ & $1(11.1)$ \\
\hline Comorbidity; $n(\%)$ & \\
\hline Cardiovascular disease & $7(77.8)$ \\
\hline Pulmonary disease & $5(55.6)$ \\
\hline History of abdominal surgery & $2(22.2)$ \\
\hline History of other malignancy & $2(22.2)$ \\
\hline \multicolumn{2}{|l|}{ ASA score $2 ; n(\%)$} \\
\hline II & $7(77.8)$ \\
\hline III & $2(22.2)$ \\
\hline \multicolumn{2}{|l|}{$\mathrm{GFI}^{3} ; n(\%)$} \\
\hline 0 & $1(11.1)$ \\
\hline $\mathrm{I}$ & $2(22.2)$ \\
\hline II & $1(11.1)$ \\
\hline III & $1(11.1)$ \\
\hline IV & $2(22.2)$ \\
\hline $\mathrm{V}$ & $2(22.2)$ \\
\hline
\end{tabular}


Table 1. Cont.

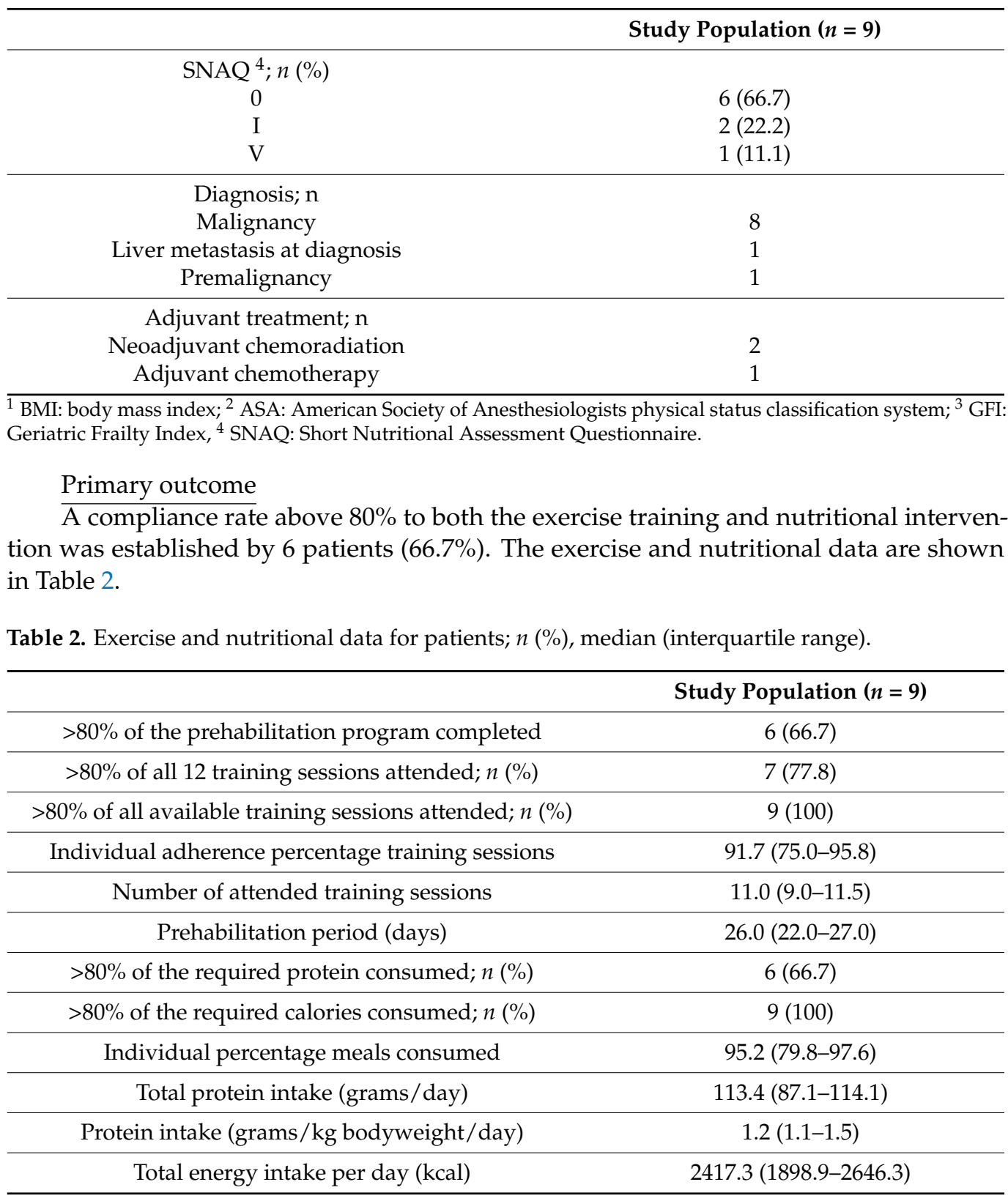

\subsection{Adherence Prehabilitation}

Seven patients $(77.8 \%)$ attended $\geq 80 \%$ of all 12 training; all patients $(100 \%)$ attended more than $80 \%$ of the available training sessions. Individual attendance to the 12 training sessions ranged from $75.0-95.8 \%$ with a median of $91.7 \%$, and 2 patients $(22.2 \%)$ attended all sessions. The reason for missing training sessions was early surgery; the 2 patients who did not attend $80 \%$ of the 12 sessions were both operated before the end of the prehabilitation program. One patient attended 8 out of 8 sessions, and the other patient attended 6 out of 6 sessions. The median number of sessions attended was 11 (IQR 9-11.5), and the median prehabilitation period was 26 days.

A total of 6 patients $(66.7 \%)$ consumed more than $80 \%$ of the required protein intake, and all participants $(100 \%)$ consumed more than $80 \%$ of the required energy intake. The median percentage of consumed meals and snacks was 95.2\% (IQR 79.8-97.6\%), and one patient consumed all meals and snacks. The median protein intake $(\mathrm{g} / \mathrm{kg} /$ day) was 1.2 (IQR 1.1-1.5), and the median energy intake was 2417.3 kcal per day (IQR 1898.9-2646.3). 
All participants (100\%) only consumed food provided by Daily Fresh Food; no other nutriments were consumed. No adverse effects related to prehabilitation were reported.

Secondary outcomes

\subsection{Organizational Feasibility}

Meals were delivered 3-4 times per week in the hospital and were provided during the training sessions. Overall, food was delivered according to schedule in all but one case $(98.7 \%)$, this delivery was postponed for one day due to a roadblock.

\subsection{Acceptability of the Interventions}

The majority of the patients had a positive food experience; $77.8 \%$ rated the taste and quality as good or excellent. The number of meals was considered a lot $(n=6,66.7 \%)$ or too much $(n=2,22.2 \%)$, and meal portions were considered sufficient $(n=7,77.8 \%)$.

The training program was appraised as good or excellent by all patients; most patients rated the intensity as sufficient $(n=4,44.4 \%)$ or heavy $(n=4,44.4 \%)$. The number of training sessions was appropriate $(n=9,100 \%)$, and the length of sessions was sufficient $(n=7,77.8 \%)$.

Generally, patients accepted the extra hospital visits $(n=5,55.5 \%)$ but four patients considered the extra visits burdensome.

\subsection{Physical Outcome Measures}

Descriptive statistics for the physical outcomes are presented in Table 3. Figures 2-5 show the physical measurements of all patients before and after prehabilitation. After prehabilitation, a median improvement of $+2 \mathrm{~kg}$ (IQR 1.1-2.0) in handgrip strength $(\mathrm{kg})$ was observed $(p=0.02, Z=-2.41)$ and a median improvement of +13 Watt (IQR 6.0-27.0) was observed in exercise capacity ( $p=0.02, Z=-2.37$ ). No difference was observed in the median maximum oxygen uptake $\left(\mathrm{VO}_{2} \mathrm{max}\right)$ before and after prehabilitation; 16.25 (IQR 13.18-24.18) versus 17.55 (IQR 12.95-21.23), nor was a difference observed in median oxygen uptake at Ventilatory Anaerobic Threshold (VAT); 12.60 (IQR 9.65-17.15) versus 13.55 (IQR 9.68-17.55). Muscle strength, measured in one-repetition maximum (1 RM) of lower and upper extremity musculature, had increased during the program in all patients.

Table 3. Physical outcomes; median (interquartile range).

\begin{tabular}{cccccc}
\hline & Pre-Prehabilitation & Post-Prehabilitation & Difference & $p$-Value & Z-Value \\
\hline Handgrip strength & $32.00(24.80-34.85)$ & $32.00(26.25-34.75)$ & $2(1.1-2.0)$ & 0.02 & -2.41 \\
\hline $\mathrm{VO}_{2} \mathrm{max}^{1} \mathrm{~mL} / \mathrm{min} / \mathrm{kg}$ & $16.25(13.18-24.18)$ & $17.55(12.95-21.23)$ & $0.0(-0.5-2.5)$ & 0.60 & -0.53 \\
\hline $\mathrm{VO}_{2} \mathrm{max}$ at $\mathrm{AT}^{2} / \mathrm{kg}$ & $12.60(9.65-17.15)$ & $13.55(9.68-17.55)$ & $-0.25(-3.15-1.55)$ & 0.67 & 0.67 \\
\hline $\begin{array}{c}\text { Maximum exercise } \\
\text { capacity (Watt) }\end{array}$ & $69.00(62.00-124.00)$ & $75.00(55.50-143.25)$ & $13(6.0-27.0)$ & 0.02 & -2.37 \\
\hline $\mathrm{FVC}^{3}$ (liter) & $2.86(2.71-4.42)$ & $3.19(2.66-4.07)$ & $0.06(-0.16-0.32)$ & 0.48 & -0.70 \\
\hline $\mathrm{FEV1}^{4}$ (liter) & $2.32(1.05-3.35)$ & $2.19(1.12-3.47)$ & $0.03(-0.04-0.12)$ & 0.57 & -0.56 \\
\hline
\end{tabular}

${ }^{1} \mathrm{VO}_{2}$ Max: maximal oxygen uptake, ${ }^{2} \mathrm{AT}$ : aerobic threshold point, ${ }^{3} \mathrm{FVC}$ : forced vital capacity, ${ }^{4} \mathrm{FEV} 1$ : forced expiratory volume in $1 \mathrm{~s}$.

\subsection{Surgical Outcomes}

Table 4 provides an overview of surgical outcomes. Surgery was performed in six patients. Three participants were not operated as one patient was diagnosed with liver metastasis requiring neoadjuvant therapy, one patient had a complete response to the neoadjuvant therapy, and one patient was diagnosed with a benign lesion for which no operation was required (these decisions were made after inclusion). Complications occurred in 2 out of 6 patients (33\%). One minor complication (tachycardia) occurred (for which a beta blocker was prescribed), and one severe complication (iatrogenic small bowel 
perforation) occurred, which required reoperation. Upon one year follow-up, no mortality was registered.

\section{Handgrip strength}

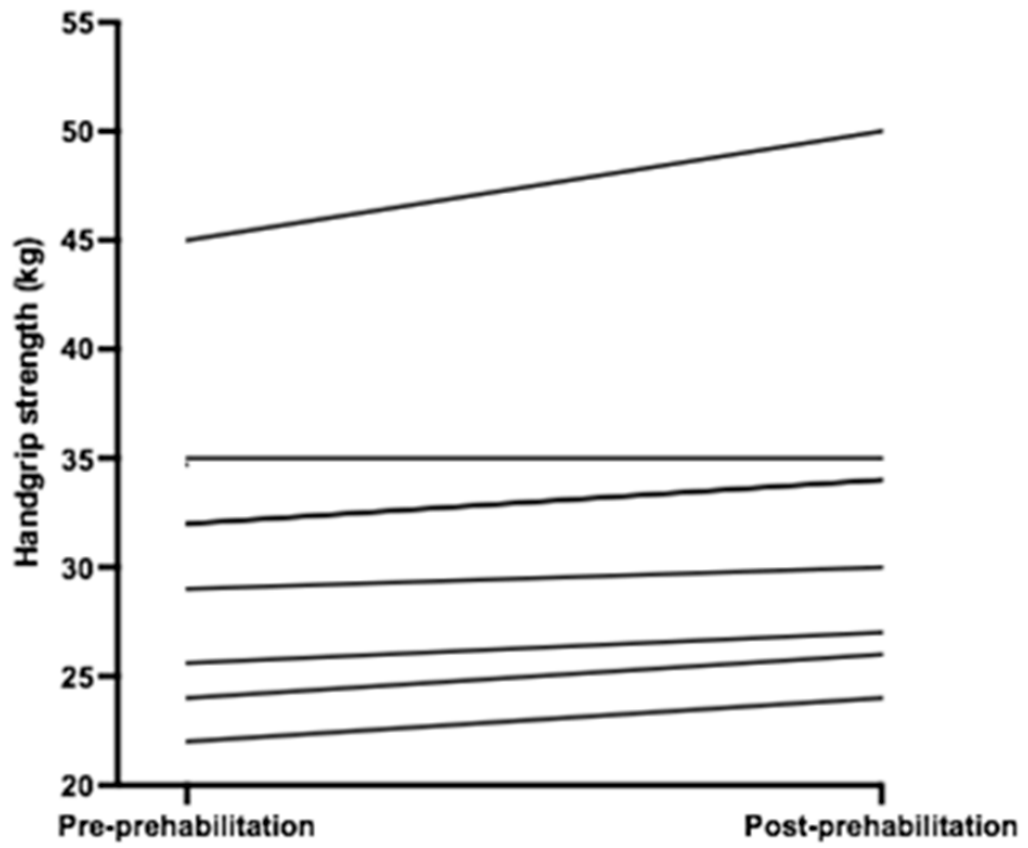

Figure 2. Handgrip strength $(\mathrm{kg})$ before and after prehabilitation.

Maximum exercise capacity (Watt)

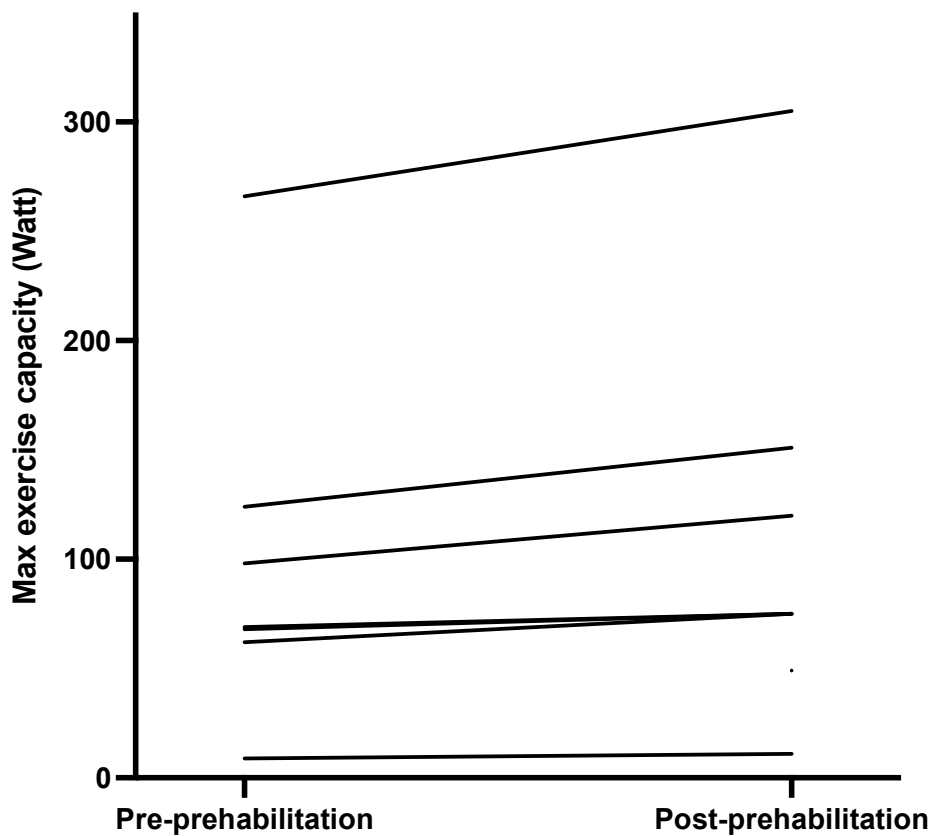

Figure 3. Maximum exercise capacity (Watt) before and after prehabilitation. 


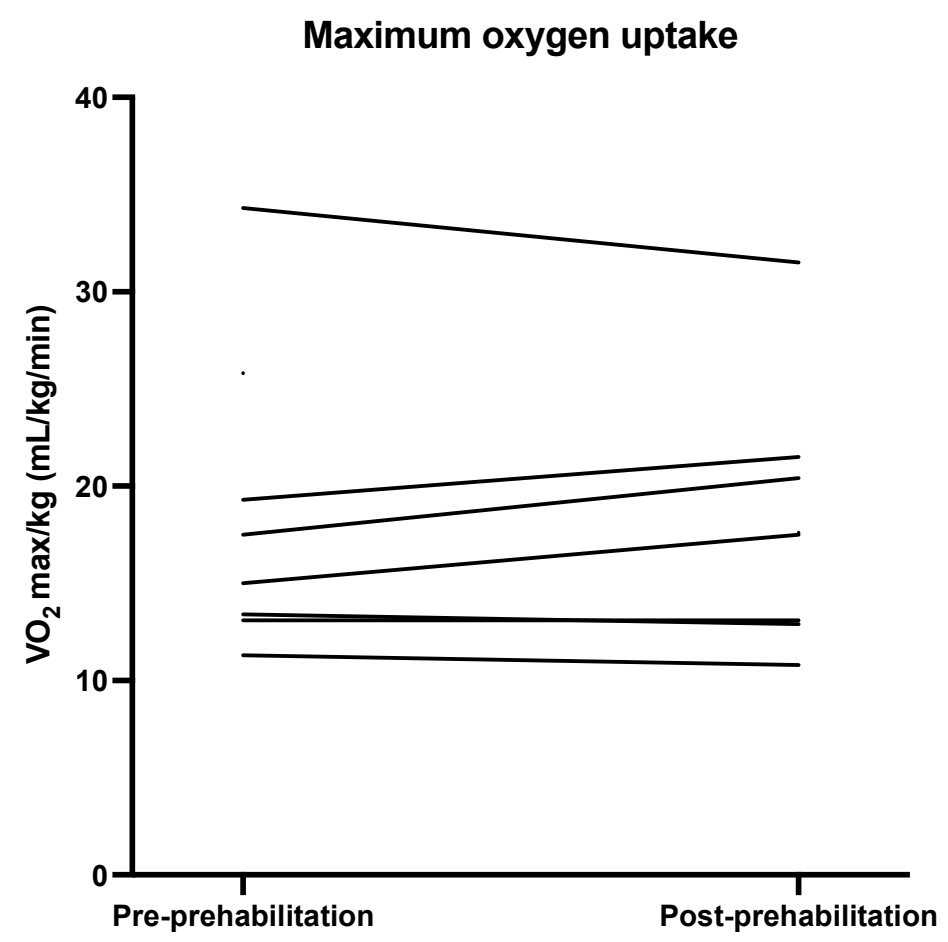

Figure 4. Maximum oxygen uptake $(\mathrm{mL} / \mathrm{kg} / \mathrm{min})$ before and after prehabilitation.

Oxygen uptake at Ventilatory Anaerobic Threshold

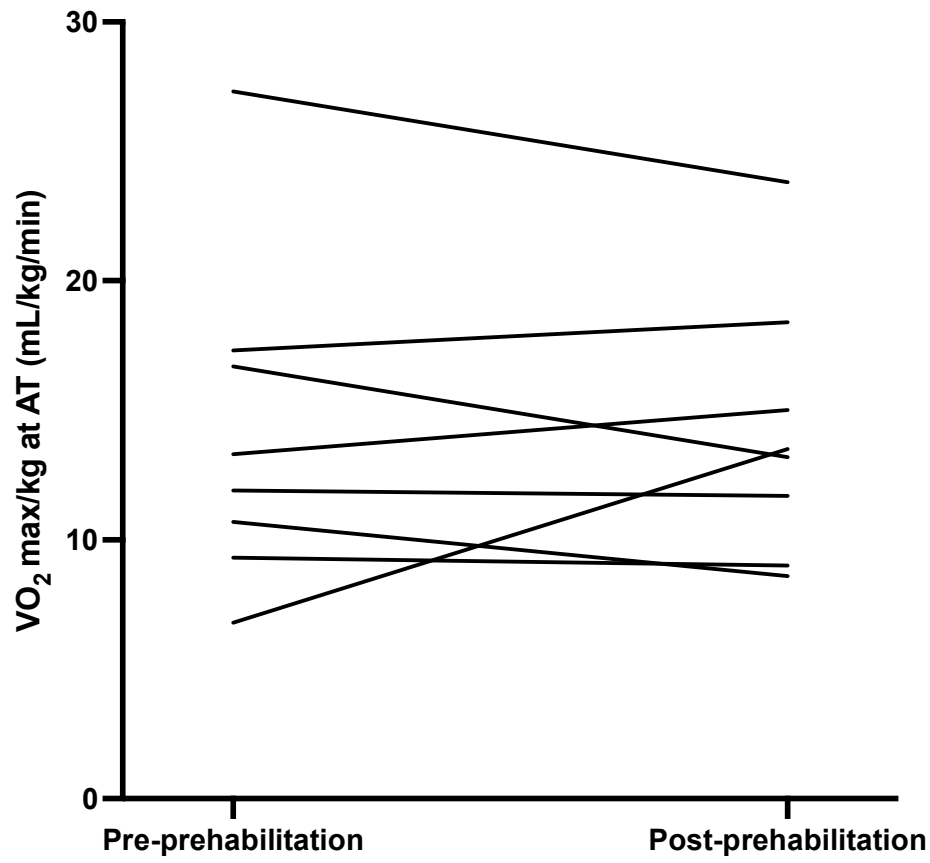

Figure 5. Oxygen uptake at Ventilatory Anaerobic Threshold (VAT) before and after prehabilitation. 
Table 4. Surgical outcomes; number (percentages), median (IQR).

\begin{tabular}{cc}
\hline & Study Population $(\boldsymbol{n}=\mathbf{9})$ \\
\hline Surgery; $n(\%)$ & 6 \\
Left hemicolectomy & $1(16.7)$ \\
Right hemicolectomy & $4(66.7)$ \\
Sigmoidectomy & $1(16.7)$ \\
\hline Re-admission <30 days & 0 \\
\hline Complication; $n$ (\%) & $2 / 6(33.3)$ \\
Microperforation & $1(16.7)$ \\
Tachycardia & $1(16.7)$ \\
\hline Clavien Dindo, $n$ & 1 (Tachycardia) $(16.7)$ \\
II & 1 (Perforation) $(16.7)$ \\
IIIb & $4(3.0-8.8)$ \\
\hline Length of hospital stay (days) & 0 \\
\hline 30-day mortality; $n$ & 0 \\
\hline 1-year mortality; $n$ &
\end{tabular}

\section{Discussion}

The present study is, to our knowledge, the first prospective study specifically focusing on the feasibility of the BEFORE multimodal prehabilitation program that combined a personalized and supervised exercise training program (to enhance physical capacity) with freshly prepared protein-rich meals (to support the required protein and energy intake), for patients 65 years and older with colorectal malignancy scheduled for elective surgery.

This study showed that this multimodal prehabilitation program was feasible for the majority of the elderly patients included in this study. The organization of the program was found to be feasible and the interventions acceptable for the population. We observed a small increase in exercise capacity and muscular strength. No adverse events directly related to the prehabilitation program were reported.

The high adherence rate to this multimodal program reflects the reports of Carli et al. and Van Rooijen et al. [24,39], who reported a prehabilitation attendance rate of at least $80 \%$. Other reported compliance rates to multimodal prehabilitation programs prior to elective abdominal cancer surgery ranged from 59 to 98 per cent [21].

On the other hand, the recruitment rate in this study was low. This was in accordance with several prior previous studies $[40,41]$. The most common reason for refusal of participation in this study was that the program was considered to be too demanding. This may be due to the fact that a recent diagnosis of cancer with forthcoming surgery negatively impacts the incentive to participate in multimodal prehabilitation programs. Furthermore, difficulty to travel to the hospital (e.g., dependency of transportation) or patients' inability to combine the prehabilitation program with the role of informal caregiver (e.g., to spouse or family member), affected their willingness to participate. It has been previously noted that, in the older adult population, the number needed to screen for inclusion is 1:3 [42]. In contrast, the recruitment rate in studies assessing multimodal prehabilitation with home-based exercise training or a shorter prehabilitation program was higher $[15,20,43]$. This suggests that the recruitment rate of this multimodal prehabilitation program could be increased by organizing training sessions in the near residential area; preferably supervised home-based or community-based exercise training. The supervised exercise training sessions was considered a specific strength of this study, since supervision increases adherence to exercise programs [44].

The organization of training sessions in the outpatient setting was uncomplicated; all intended sessions were organized by a dedicated team. The Dutch guidelines state that treatment of colorectal cancer has to be effected within 7 weeks after diagnosis [45], generally surgery is performed within 5 weeks following diagnosis [46]. The oncological outcome does not improve when colorectal patients are operated within these 5 weeks [47]. 
In this study, all patients were operated within this time window, some were operated before the end of the prehabilitation program. In one case this was due to the COVID-19 pandemic, and the other operation was rescheduled due to postponement of another operation. Even though a 4-week prehabilitation program may be feasible, this raises the question whether this prehabilitation program can be realized for all patients, since time between diagnosis and operation might be less than 4 weeks for various reasons.

In general, the overall success rate of food delivery was high; only one delivery was postponed. Nonetheless, arranging food delivery on the training days was rather complex. As patients entered the prehabilitation program on different moments, providing patients with the correct meal boxes required careful and detailed organization. An alternative could be home delivery, which is easier to organize.

\section{Acceptability of Interventions}

In general, participants considered the interventions to be acceptable in terms of frequency and intensity of physical training, and regarding number and taste of the meals.

In contrast to the majority of literature focusing on nutritional support by consultation of a dietician and/or oral nutritional supplements, in this study exercise training and 6 freshly prepared meals for 4 weeks were combined. Because the taste of oral nutritional supplements (ONS) may be disliked [48], this study aimed to increase adherence to the nutritional intervention and to improve food experience. Positively, the adherence to the nutritional program was high (95.2\%). Of the three modalities used to accurately calculate the macronutrient intake, the food diary appeared to be the most feasible and accessible method. Adherence to the nutritional intervention was consistent with prior reports [26,27]. In these studies a food diary or interview was applied to assess compliance, no objective measurements were included.

Testing physical capacity using CPET was complicated for two patients $(22.2 \%)$ due to cycling difficulties: one patient was unable to cycle due to balance disorder and one patient could only cycle with low resistance because of an artificial knee. In follow-up studies, other modalities to test vital capacity could be considered.

Due to the small study sample, no conclusion can be drawn regarding the correlation between prehabilitation and both functional and surgical outcomes.

Improvement of some aspects of the physical capacity, including exercise capacity, muscular strength, and a minor increase in FVC and FEV1 were observed during this prehabilitation program. However, the improvement in handgrip strength was below the minimally clinically important difference of at least $5 \mathrm{~kg}$ as described in the literature $[49,50]$. There is a lack of evidence of the minimal clinically important difference for the other parameters.

Increase in exercise capacity was also reported by Barberan et al. and Liu et al., demonstrating a significant improvement of aerobic capacity [51,52]. Increase in FVC was consistent with the study of Liu et al., who demonstrated an improvement in FVC after two weeks of multimodal prehabilitation [52]. Reported enhancement in peak $\mathrm{VO}_{2}$ and VAT was not corroborated by the findings of this study [53]. A possible explanation for this difference might be that the patients included in this study were generally in better physical shape than patients in previous studies, characterized by relatively low ASA score, and rather high $\mathrm{VO}_{2}$ max and VAT. Increase in muscular strength was consistent with previous studies $[39,53]$.

The overall complication rate was in accordance with a few studies $[15,16]$, but not all prior studies [24,53], potentially due to difference in age and in other patient characteristics.

Limitations

This study was limited by the low recruitment rate. This could result in selection bias; patients with affinity for training could be more inclined to participate in a prehabilitation program. This may have affected validity and generalizability of study findings. Since this was a feasibility study with a small study population no conclusions regarding the effect of prehabilitation on functional and surgical outcomes could be drawn. However, 
the aim of this study was to assess the feasibility of the prehabilitation program, this could be determined.

Baseline information of non-participating patients was not collected in this study; therefore no comparison between these patient-groups can be accomplished. Nonetheless, reasons for refusal were collected and will be taken into account in subsequent studies.

Furthermore, measuring all nutritional intake for one week appeared to be complex. The three measurement methods (weighing, taking pictures and keeping a food diary) had to be performed frequently, for some participants it proved to be difficult to perform all these measurements correctly. Some patients forgot to determine their food intake, various pictures were blurred, and keeping a food diary was demanding. The results regarding intake presented in this study therefore may underestimate the real nutritional intake. However, unlike previous studies, in this study intake was objectively measured, yielding a more accurate result than subjective measurements [26,27].

Although patients included in this study considered the program to be acceptable, recruiting patients proved difficult. To optimize the feasibility of a study like this, efforts should be made to ensure that all eligible patients are willing and able to participate in the prehabilitation program. The recruitment pathway should be further investigated, preferably including qualitative analysis of considerations regarding participation. Moreover, opportunities of prehabilitation with supervised community- or homebased exercise training must be further investigated. In addition to CPET, reliability and tolerance of measuring physical function with other tests should be investigated. The effects of this personalized multimodal prehabilitation program may be explored on a larger scale to analyze and corroborate the effect on functional capacity and postoperative outcomes. A pilot study was designed to further assess the effects of this prehabilitation program, but its start has been postponed until after the Corona pandemic.

\section{Conclusions}

In this study it has been demonstrated that personalized multimodal prehabilitation with supervised exercise training combined with protein-rich meals prior to colorectal resection for (pre)malignancy is feasible for at least two-third of the participants. Most patients completed $>80 \%$ of the prehabilitation program. The program was also feasible in terms of organization and application for participants. Improvement in some aspects of physical capacity was suggested. In order to improve recruitment rate, modifications for a definitive trial should be considered and implemented, whilst statistical power may be calculated with the demonstrated effects of multimodal prehabilitation programs.

Author Contributions: Conceptualization, J.H.M.B.S., A.A.V.B., W.M.W.H.S., E.-J.G.B., T.T.T.T. and N.C.V.N.; methodology, J.H.M.B.S. and T.T.T.T.; formal analysis, T.T.T.T., M.A.T.S. and J.H.M.B.S.; investigation, T.T.T.T., J.H.M.B.S.; resources, J.H.M.B.S.; data curation, T.T.T.T., M.A.T.S. and J.H.M.B.S.; protocol J.H.M.B.S., A.A.V.B., E.-J.G.B., T.T.T.T. and N.C.V.N.; writing-original draft preparation, T.T.T.T., M.A.T.S. and J.H.M.B.S.; writing-review and editing, T.T.T.T., M.A.T.S. and J.H.M.B.S., E.-J.G.B., A.A.V.B., W.M.W.H.S. and N.C.V.N.; supervision, J.H.M.B.S., A.A.V.B., E.-J.G.B.; project administration, J.H.M.B.S. and N.C.V.N. All authors have read and agreed to the published version of the manuscript.

Funding: Daily Fresh Food Inc. ${ }^{\circledR}$ developed, produced, and provided subjects with the required products for the nutritional intervention. In addition, the Research and Innovation Fund Zuyderland, Parkstad Culinair and the Rabobank provided funding to conduct this study. The funders had no role in study design, data collection, analysis and the interpretation of data or in writing of the manuscript.

Institutional Review Board Statement: The study was conducted according to the guidelines of the Declaration of Helsinki, and approved by the 'Medisch-Etische Toetsingscommissie Zuyderland (METC Z) (Medical Research Ethics Committee (MREC) Zuyderland) (NL70834.096.19/11-07-2019).

Informed Consent Statement: Informed consent was obtained from all subjects involved in the study.

Data Availability Statement: Data are available upon request from the first author (T.T.T. Tweed). 
Acknowledgments: We thank the members of the prehabilitation team in Zuyderland Medical Centre, the Sport and Exercise Physicians P. Grandjean Perrenod Comtesse, P. Dobbelaar and H. Schipper. The dieticians V. Voskuilen and M. van der Werf. The nurse practitioners I. Daher, R. Sormani, K. Gubbels and I. Stohr, promotor J.W.M. Greve, and Daily Fresh Food employees R. Bartels, E. Gehlen, M. Hengeveld, and M. Bisselink.

Conflicts of Interest: The funders had no role in the design of the study; in the collection, analyses, or interpretation of data; in the writing of the manuscript, or in the decision to publish the results.

\section{Appendix A}

Patient Evaluation Form-BEFORE (nutrition and exercise)

Based on your experience before admission, fill in your opinion on the following topics: nutrition, exercise and experience. Circle the number that represents your experience.

\section{General}

What did you think of this program? What grade would you give it?

$\begin{array}{rlllllllll}\text { Bad } & & & & & & \text { Excellent } \\ 1 & 2 & 3 & 4 & 5 & 6 & 7 & 8 & 9 & 10\end{array}$

How satisfied are you with this program?

\begin{tabular}{lcccc} 
Very dissatisfied & Dissatisfied & Neutral & Satisfied & Very Satisfied \\
\hline 1 & 2 & 3 & 4 & 5
\end{tabular}

Would you recommend this program to others?

\begin{tabular}{lcc} 
Not at all & Maybe & Certainly \\
\hline 1 & 2 & 3
\end{tabular}

Nutrition

What did you think of the taste of the meals?

\begin{tabular}{lcccc} 
Bad & Moderate & Acceptable & Good & Excellent \\
\hline 1 & 2 & 3 & 4 & 5
\end{tabular}

What did you think of the quality of the meals?

\begin{tabular}{lcccc} 
Bad & Moderate & Acceptable & Good & Excellent \\
\hline 1 & 2 & 3 & 4 & 5
\end{tabular}

What did you think of the number of meals per day?

\begin{tabular}{lcrrr} 
Too few & Few & Sufficient & Many & Too many \\
\hline 1 & 2 & 3 & 4 & 5
\end{tabular}

What did you think of the portions of the meals?

$\begin{array}{lcccc}\text { Too little } & \text { Little } & \text { Sufficient } & \text { A lot } & \text { Too much } \\ 1 & 2 & 3 & 4 & 5\end{array}$

\section{Exercise}

What did you think of the training program (with the physiotherapist)?

\begin{tabular}{ccccc} 
Bad & Mediocre & Acceptable & Good & Excellent \\
\hline 1 & 2 & 3 & 4 & 5
\end{tabular}

What did you think of the intensity of the training sessions?

\begin{tabular}{lcccc} 
Not challenging & Little challenging & Acceptable & Heavy & Too heavy \\
\hline 1 & 2 & 3 & 4 & 5
\end{tabular}

What did you think of the number of training moments?

\begin{tabular}{lccrc} 
Too few & Few & Sufficient & Many & Too many \\
\hline 1 & 2 & 3 & 4 & 5
\end{tabular}

What did you think of the duration of each training moment?

\begin{tabular}{lcccc} 
Too short & Short & Acceptable & Long & Too long \\
\hline 1 & 2 & 3 & 4 & 5
\end{tabular}

EXTRA

How stressful were the number of extra visits to the hospital?

Not burdensome Little burdensome Acceptable Very burdensome Too burdensome

\begin{tabular}{lllll}
\hline 1 & 2 & 3 & 4 & 5
\end{tabular}




\section{Appendix B}
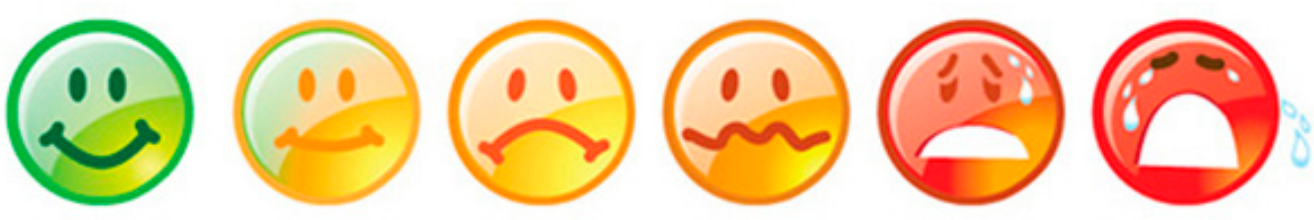

Figure A1. VAS score appetite (1st screening).
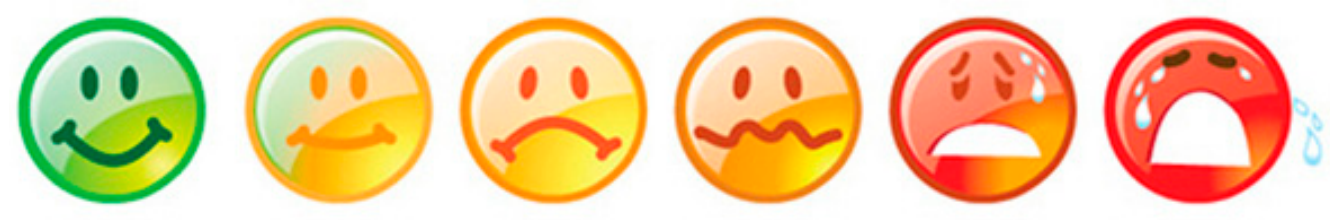

Figure A2. VAS score appetite (2nd screening).
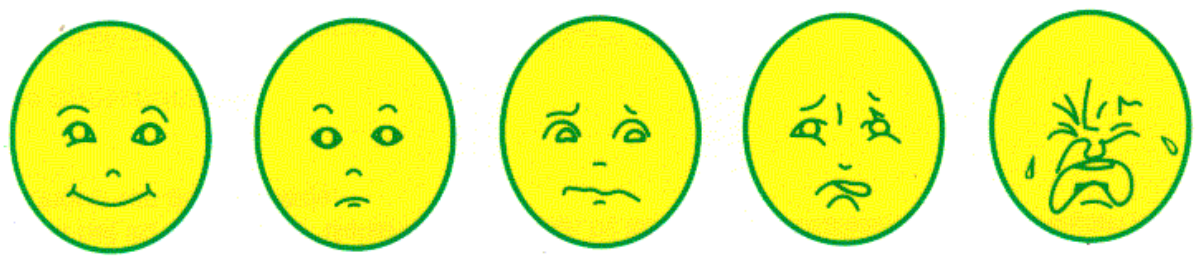

Figure A3. VAS score food experience (2nd screening).

\section{Appendix C}

Section of the Menu

Table A1. Breakfast 1.

\begin{tabular}{clll}
\hline Description & Portion & Product Weight (gram) & Total Weight (gram) \\
\hline Multigrain bread & 2 & 35 & 70 \\
\hline Butter & 2 & 5 & 10 \\
Chicken breast & 2 & 15 & 30 \\
\hline Mature cheese & 1 & 20 & 20 \\
\hline Boiled egg & 1 & 50 & 50 \\
\hline Yogurt with muesli & 1 & 170 & 170 \\
\hline Banana & 1 & 80 & 80 \\
\hline
\end{tabular}

Table A2. Morning snack 1.

\begin{tabular}{clll}
\hline Description & Portion & Product Weight (gram) & Total Weight (gram) \\
\hline Cream puff with stuffing: & 5 & 3 & 15 \\
Curd & 1 & 40 & 40 \\
Cream & 1 & 15 & 15 \\
Mascarpone & 1 & 20 & 20 \\
Powdered sugar & 1 & 10 & 10 \\
Passion fruit & 1 & 15 & 15 \\
\hline
\end{tabular}


Table A3. Lunch 1.

\begin{tabular}{clll}
\hline Description & Portion & Product Weight (gram) & Total Weight (gram) \\
\hline Sandwich: & 2 & 35 & 70 \\
Herb cheese & 2 & 15 & 30 \\
Smoked meat & 2 & 15 & 30 \\
\hline Baked onions & 1 & 10 & 10 \\
\hline
\end{tabular}

Table A4. Lunch 2.

\begin{tabular}{clll}
\hline \multicolumn{1}{c}{ Description } & Portion & Product Weight (gram) & Total Weight (gram) \\
\hline Smoked chicken salad & & & \\
with dressing & & & \\
Salad: & 1 & 15 & 35 \\
Smoked chicken breast & 1 & 5 & 15 \\
Red pepper & 1 & 9 & 5 \\
Cucumber & 1 & 4 & 9 \\
Apple & 1 & 2 & 4 \\
Raisins & 1 & 1 & 2 \\
Shallot & 1 & 20 & 1 \\
Little yam lettuce & & 10 & 20 \\
Dressing: & 1 & 3.5 & 10 \\
Mayonnaise & 1 & 0.5 & 3.5 \\
Crème fraiche & 1 & 0.05 & 0.5 \\
Lemon juice & 1 & 0.05 & 0.05 \\
Parsley & 1 & 60 & 0.05 \\
Chives & 1 & 10 & 60 \\
Pepper & 1 & 35 & 30 \\
\hline Avocado & 3 & 35 \\
\hline Quail egg & 1 & &
\end{tabular}

Table A5. Afternoon snack 1.

\begin{tabular}{llll}
\hline \multicolumn{1}{c}{ Description } & Portion & Product Weight (gram) & Total Weight (gram) \\
\hline Red curry soup & 1 & 200 & 200 \\
\hline
\end{tabular}

Table A6. Diner 1.

\begin{tabular}{llll}
\hline \multicolumn{1}{c}{ Description } & Portion & Product Weight (gram) & Total Weight (gram) \\
\hline Grilled salmon & 1 & 80 & 80 \\
\hline Remoulade sauce: & 1 & 20 & 20 \\
Mayonnaise & 1 & 20 & 20 \\
$\quad$ Yogurt & 1 & 2 & 2 \\
Mustard & 1 & 5 & 5 \\
Capers & 1 & 3 & 3 \\
Shallot & 1 & 0.0001 & 0.0001 \\
$\quad$ Pepper & 2 & 150 & 300 \\
\hline Mashed potatoes with & 1 & 150 & 150 \\
parmesan & 1 & 125 & 125 \\
\hline Peas & 1 & 25 & 25 \\
\hline Cottage cheese & & & \\
dessert & 1 & & \\
\hline
\end{tabular}


Table A7. Evening snack 1.

\begin{tabular}{clll}
\hline Description & Portion & Product Weight (gram) & Total Weight (gram) \\
\hline Chicken meatball: & & & \\
Chicken breast & 2 & 14.5 & 29 \\
Chicken thigh & 2 & 27 & 54 \\
Water & 2 & 2.5 & 5 \\
Chicken seasoning & 2 & 1.5 & 3 \\
Bread-crumbs & 2 & 1.5 & 3 \\
Egg & 2 & 3 & 6 \\
\hline Satay sauce & 1 & 50 & 50 \\
\hline
\end{tabular}

Table A8. Breakfast 2.

\begin{tabular}{clll}
\hline Description & Portion & Product Weight (gram) & Total Weight (gram) \\
\hline Whole grain bread & 2 & 35 & 70 \\
Butter & 2 & 5 & 10 \\
Smoked meat & 1 & 25 & 25 \\
Mature cheese & 1 & 20 & 20 \\
Tomato & 1 & 70 & 70 \\
Omelet & 1 & 90 & 90 \\
\hline
\end{tabular}

Table A9. Morning snack 2.

\begin{tabular}{cccc}
\hline Description & Portion & Product weight (gram) & Total weight (gram) \\
\hline $\begin{array}{c}\text { Brownie } \\
\text { chocolate/hazelnut }\end{array}$ & 1 & 125 & 125 \\
\hline
\end{tabular}

Table A10. Lunch 3.

\begin{tabular}{clll}
\hline Description & Portion & Product Weight (gram) & Total Weight (gram) \\
\hline Chicken and bean burger: & & 55 & 55 \\
Minced chicken & 1 & 4 & 4 \\
Bread-crumbs & 1 & 3 & 3 \\
Egg & 1 & 1 & 1 \\
Lemon juice & 1 & 1.8 & 1.8 \\
Mascarpone & 1 & 2 & 2 \\
Coconut milk & 1 & 0.2 & 0.2 \\
Coriander & 1 & 1 & 1 \\
Parsley & 1 & 8 & 8 \\
Kidney beans & 1 & 3 & 3 \\
Shallot & 1 & 1 & 1 \\
Salt & 1 & & \\
Brioche bun with pickle: & & 35 & 35 \\
Brioche bun & 1 & 15 & 15 \\
Pickle & 1 & & \\
Yogurt dip & & 20 & 20 \\
Low-fat yogurt & 1 & 15 & 15 \\
Crème fraiche & 1 & 1 & 1 \\
Parsley & 1 & 0.05 & 0.05 \\
Garlic clove powder & 1 & 1 & 1 \\
Lime juice & 1 & 0.5 & 0.5 \\
Salt & 1 & &
\end{tabular}


Table A11. Afternoon snack 2.

\begin{tabular}{llll}
\hline \multicolumn{1}{c}{ Description } & Portion & Product Weight (gram) & Total Weight (gram) \\
\hline Red pepper soup & 1 & 200 & 200 \\
\hline
\end{tabular}

Table A12. Diner 2.

\begin{tabular}{llll}
\hline \multicolumn{1}{c}{ Description } & Portion & Product Weight (gram) & Total Weight (gram) \\
\hline Macaroni & 1 & 145 & 145 \\
\hline Healthy bolognaise & 1 & 145 & 145 \\
\hline Parmesan & 1 & 10 & 10 \\
\hline Cucumber salad & 1 & 50 & 50 \\
\hline Skyr with forest fruits: & & & 125 \\
$\quad$ Skyr & 1 & 125 & 8 \\
Forest fruits & & & 9 \\
Raspberry & 1 & 8 & 8 \\
$\quad$ Blueberry & 1 & 9 & \\
Strawberry & 1 & 8 &
\end{tabular}

Table A13. Evening snack 2.

\begin{tabular}{clll}
\hline Description & Portion & Product Weight (gram) & Total Weight (gram) \\
\hline Tortilla with hummus dip & & & \\
Tortilla & 1 & 25 & 25 \\
Hummus & 1 & 60 & 60 \\
\hline
\end{tabular}

\section{References}

1. Govaert, J.A.; Fiocco, M.; van Dijk, W.A.; Scheffer, A.C.; de Graaf, E.J.R.; Tollenaar, R.A.E.M.; Wouters, M.W.J.M. Costs of complications after colorectal cancer surgery in the Netherlands: Building the business case for hospitals. Eur. J. Surg. Oncol. 2015, 41, 1059-1067. [CrossRef]

2. Tevis, S.E.; Kennedy, G.D. Postoperative Complications: Looking Forward to a Safer Future. Clin. Colon Rectal Surg. 2016, 29, 246-252. [CrossRef]

3. Ripollés-Melchor, J.; Ramírez-Rodríguez, J.M.; Casans-Francés, R.; Aldecoa, C.; Abad-Motos, A.; Logroño-Egea, M.; García-Erce, J.A.; Camps-Cervantes, Á.; Ferrando-Ortolá, C.; Suarez de la Rica, A.; et al. For the POWER Study Investigators Group for the Spanish Perioperative Audit and Research Network (REDGERM) Association Between Use of Enhanced Recovery After Surgery Protocol and Postoperative Complications in Colorectal Surgery: The Postoperative Outcomes Within Enhanced Recovery After Surgery Protocol (POWER) Study. JAMA Surg. 2019, 154, 725-736. [CrossRef]

4. Ikuta, K.S.; Salimzadeh, H.; Delavari, A.; Ansari, R.; Merat, S.; Fitzmaurice, C.; Abegaz, K.H.; Akinyemiju, T.; Alikhani, M.; Alvis-Guzman, N.; et al. The global, regional, and national burden of colorectal cancer and its attributable risk factors in 195 countries and territories, 1990-2017: A systematic analysis for the Global Burden of Disease Study 2017. Lancet Gastroenterol. Hepatol. 2019, 4, 913-933. [CrossRef]

5. Sung, H.; Ferlay, J.; Siegel, R.L.; Laversanne, M.; Soerjomataram, I.; Jemal, A.; Bray, F. Global cancer statistics 2020: GLOBOCAN estimates of incidence and mortality worldwide for 36 cancers in 185 countries. CA A Cancer J. Clin. 2021. [CrossRef]

6. Nederlandse Kankerregistratie (NKR), Integraal Kankercentrum Nederland (IKNL). Available online: https://iknl.nl/ kankersoorten/darmkanker (accessed on 7 March 2021).

7. Poos, M.J.J.C. (RIVM), van der Wilk, E.A. red. (RIVM). Levensverwachting, Volksgezondheidenzorg.info. 2020. Available online: https://www.volksgezondheidenzorg.info/onderwerp/levensverwachting/cijfers-context/trends\#node-prognoselevensverwachting (accessed on 2 March 2021).

8. Vogel, J.D.; Eskicioglu, C.; Weiser, M.R.; Feingold, D.L.; Steele, S.R. The American Society of Colon and Rectal Surgeons Clinical Practice Guidelines for the Treatment of Colon Cancer. Dis. Colon Rectum 2017, 60, 999-1017. [CrossRef]

9. Audisio, R.A.; Pope, D.; Ramesh, H.S.J.; Gennari, R.; van Leeuwen, B.L.; West, C.; Corsini, G.; Maffezzini, M.; Hoekstra, H.J.; Mobarak, D.; et al. Shall we operate? Preoperative assessment in elderly cancer patients (PACE) can help A SIOG surgical task force prospective study. Crit. Rev. Oncol. Hematol. 2008, 65, 156-163. [CrossRef]

10. Nederlandse Vereniging voor Klinische Geriatrie. Comprehensive Geriatric Assessment. Nederlandse Vereniging voor Klinische Geriatrie. 2010. Available online: file:///H:/Downloads/Comprehensive_geriatric_assessment_CGA_pdf (accessed on 12 April 2021). 
11. Morley, J.E.; Vellas, B.; Van Kan, G.A.; Anker, S.D.; Bauer, J.M.; Bernabei, R.; Matteo, C.; Chumlea, W.C.; Wolfram, D.; Jonathan, E.; et al. Frailty Consensus: A Call to Action. J. Am. Med. Dir. Assoc. 2013, 14, 392-397. [CrossRef] [PubMed]

12. Partridge, J.S.L.; Harari, D.; Dhesi, J.K. Frailty in the older surgical patient: A review. Age Ageing 2012, 41, 142-147. [CrossRef] [PubMed]

13. Milder, D.A.; Pillinger, N.L.; Kam, P.C.A. The role of prehabilitation in frail surgical patients: A systematic review. Acta Anaesthesiol. Scandinavica 2018, 62, 1356-1366. [CrossRef] [PubMed]

14. Carli, F.; Zavorsky, G. Optimizing functional exercise capacity in the elderly surgical population. Curr. Opin. Clin. Nutr. Metab. Care 2005, 8, 23-32. [CrossRef] [PubMed]

15. Gillis, C.; Li, C.; Lee, L.; Awasthi, R.; Augustin, B.; Gamsa, A.; Liberman, A.; Stein, B.; Charlebois, P.; Feldman, L.; et al. Prehabilitation versus Rehabilitation: A Randomized Control Trial in Patients Undergoing Colorectal Resection for Cancer. Anesthesiology (Philadelphia) 2014, 121, 937-947. [CrossRef]

16. Minnella, E.M.; Awasthi, R.; Gillis, C.; Fiore, J.F.; Liberman, A.S.; Charlebois, P.; Stein, B.; Bousquet-Dion, G.; Feldman, L.S.; Carli, F.; et al. Patients with poor baseline walking capacity are most likely to improve their functional status with multimodal prehabilitation. Surgery 2016, 160, 1070-1079. [CrossRef] [PubMed]

17. Minnella, E.M.; Bousquet-Dion, G.; Awasthi, R.; Scheede-Bergdahl, C.; Carli, F. Multimodal prehabilitation improves functional capacity before and after colorectal surgery for cancer: A five-year research experience. Acta Oncol. 2017, 56, 295-300. [CrossRef]

18. Hughes, M.; Hackney, R.; Lamb, P.; Wigmore, S.; Christopher Deans, D.; Skipworth, R. Prehabilitation Before Major Abdominal Surgery: A Systematic Review and Meta-analysis. World J. Surg. 2019, 43, 1661-1668. [CrossRef] [PubMed]

19. Waterland, J.L.; McCourt, O.; Edbrooke, L.; Granger, C.L.; Ismail, H.; Riedel, B.; Denehy, L. Efficacy of Prehabilitation Including Exercise on Postoperative Outcomes Following Abdominal Cancer Surgery: A Systematic Review and Meta-Analysis. Front Surg. 2021, 8, 628848. [CrossRef]

20. Bousquet-Dion, G.; Awasthi, R.; Loiselle, S.; Minnella, E.M.; Agnihotram, R.V.; Bergdahl, A.; Carli, F.; Scheede-Bergdahl, C. Evaluation of supervised multimodal prehabilitation programme in cancer patients undergoing colorectal resection: A randomized control trial. Acta Oncol. 2018, 57, 849-859. [CrossRef] [PubMed]

21. Daniels, S.L.; Lee, M.J.; George, J.; Kerr, K.; Moug, S.; Wilson, T.R.; Brown, S.R.; Wyld, L. Prehabilitation in elective abdominal cancer surgery in older patients: Systematic review and meta-analysis. BJS Open 2020, 4, 1022-1041. [CrossRef]

22. McIsaac, D.I.; Jen, T.; Mookerji, N.; Patel, A.; Lalu, M.M. Interventions to improve the outcomes of frail people having surgery: A systematic review. PLoS ONE 2017, 12, e0190071. [CrossRef]

23. Carli, F.; Charlebois, P.; Stein, B.; Feldman, L.; Zavorsky, G.; Kim, D.J.; Scott, S.; Mayo, N.E. Randomized clinical trial of prehabilitation in colorectal surgery. Br. J. Surg. 2010, 97, 1187-1197. [CrossRef]

24. Carli, F.; Bousquet-Dion, G.; Awasthi, R.; Elsherbini, N.; Liberman, S.; Boutros, M.; Stein, B.; Charlebois, P.; Ghitulescu, G.; Morin, N.; et al. Effect of Multimodal Prehabilitation vs. Postoperative Rehabilitation on 30-Day Postoperative Complications for Frail Patients Undergoing Resection of Colorectal Cancer: A Randomized Clinical Trial. JAMA Surg. 2020, 155, 233-242. [CrossRef]

25. Looijaard, S.M.L.M.; Slee-Valentijn, M.; Otten, R.H.J.; Maier, A.B. Physical and Nutritional Prehabilitation in Older Patients With Colorectal Carcinoma: A Systematic Review. J. Geriatr. Phys. Ther. 2018, 41, 236-244. [CrossRef] [PubMed]

26. Bruns, E.R.J.; Argillander, T.E.; Van Den Heuvel, B.; Buskens, C.J.; Van Duijvendijk, P.; Winkels, R.M.; Kalf, A.; Van Der Zaag, E.S.; Wassenaar, E.B.; Bemelman, W.A.; et al. Oral Nutrition as a Form of Pre-Operative Enhancement in Patients Undergoing Surgery for Colorectal Cancer: A Systematic Review. Surg. Infect. 2018, 19, 1-10. [CrossRef]

27. Gillis, C.; Buhler, K.; Bresee, L.; Carli, F.; Gramlich, L.; Culos-Reed, N.; Sajobi, T.T.; Fenton, T.R. Effects of Nutritional Prehabilitation, With and Without Exercise, on Outcomes of Patients Who Undergo Colorectal Surgery: A Systematic Review and Meta-analysis. Gastroenterology 2018, 155, 391-410. [CrossRef]

28. Weimann, A.; Braga, M.; Carli, F.; Higashiguchi, T.; Hübner, M.; Klek, S.; Laviano, A.; Ljungqvist, O.; Lobo, D.N.; Martindale, R.; et al. ESPEN guideline: Clinical nutrition in surgery. Clin. Nutr. 2017, 36, 623-650. [CrossRef]

29. Harris, J.A.; Benedict, F.G. A Biometric Study of Human Basal Metabolism. Proc. Natl. Acad. Sci. USA 1918, 4, 370-373. [CrossRef]

30. Kruizenga, H.M.; Seidell, J.C.; de Vet, H.C.W.; Wierdsma, N.J.; van Bokhorst-de van der Schueren, M.A.E. Development and validation of a hospital screening tool for malnutrition: The short nutritional assessment questionnaire (SNAQ@). Clin. Nutr. 2005, 24, 75-82. [CrossRef]

31. Steverink, N.; Slaets, J.; Schuurmans, H.; Lis, M. Measuring frailty: Developing and testing the GFI (Groningen Frailty Indicator). Gerontologist 2001, 41, 236-237.

32. Aaronson, N.K.; Ahmedzai, S.; Bergman, B.; Bullinger, M.; Cull, A.; Duez, N.J.; Filiberti, A.; Flechtner, H.; Fleishman, S.B.; Haes, J.C.J.M.; et al. The European Organization for Research and Treatment of Cancer QLQ-C30: A Quality-of-Life Instrument for Use in International Clinical Trials in Oncology. JNCI J. Natl. Cancer Inst. 1993, 85, 365-376. [CrossRef]

33. Freyd, M. The Graphic Rating Scale. J. Educ. Psychol. 1923, 14, 83-102. [CrossRef]

34. Mishra, S.I.; Scherer, R.W.; Snyder, C.; Geigle, P.M.; Berlanstein, D.R.; Topaloglu, O. Exercise interventions on health-related quality of life for people with cancer during active treatment. Clin. Otolaryngol. 2012, 37, 390-392. [CrossRef]

35. Mazzeo, R.S.; Tanaka, H. Exercise Prescription for the Elderly: Current Recommendations. Sports Med. 2001, 31, 809-818. [CrossRef]

36. Borg, G.A. Psychophysical bases of perceived exertion. Med. Sci. Sports Exerc. 1982, 14, 377-381. [CrossRef] 
37. Clavien, P.A.; Barkun, J.; de Oliveira, M.L.; Vauthey, J.N.; Dindo, D.; Schulick, R.D.; de Santibañes, E.; Pekolj, J.; Slankamenac, K.; Bassi, C.; et al. The Clavien-Dindo Classification of Surgical Complications: Five-Year Experience. Ann. Surgery 2009, 250, 187-196. [CrossRef]

38. Dindo, D.; Demartines, N.; Clavien, P.A. Classification of surgical complications: A new proposal with evaluation in a cohort of 6336 patients and results of a survey. Ann. Surg. 2004, 240, 205-213. [CrossRef]

39. van Rooijen, S.; Molenaar, C.; Schep, G.; van Lieshout, R.; Beijer, S.; Dubbers, R.; Rademakers, N.; Papen-Botterhuis, N.; van Kempen, S.; Carli, F.; et al. Making Patients Fit for Surgery: Introducing a Four Pillar Multimodal Prehabilitation Program in Colorectal Cancer. Am. J. Phys. Med. Rehabil. 2019, 98, 888-896. [CrossRef]

40. Karlsson, E.; Farahnak, P.; Franzen, E.; Nygren-Bonnier, M.; Dronkers, J.; van Meeteren, N.; Rydwik, E. Feasibility of preoperative supervised home-based exercise in older adults undergoing colorectal cancer surgery-A randomized controlled design. PLoS ONE 2019, 14, e0219158. [CrossRef] [PubMed]

41. Northgraves, M.J.; Arunachalam, L.; Madden, L.A.; Marshall, P.; Hartley, J.E.; MacFie, J.; Vince, R.V. Feasibility of a novel exercise prehabilitation programme in patients scheduled for elective colorectal surgery: A feasibility randomised controlled trial. Supportive Care Cancer 2020, 28, 3197-3206. [CrossRef] [PubMed]

42. McMurdo, M.E.T.; Roberts, H.; Parker, S.; Wyatt, N.; May, H.; Goodman, C.; Jackson, S.; Gladman, J.; O’Mahony, S.; Ali, K.; et al. Improving recruitment of older people to research through good practice. Age Ageing 2011, 40, 659-665. [CrossRef]

43. Dronkers, J.; Lamberts, H.; Reutelingsperger, I.; Naber, R.; Dronkers-Landman, C.; Veldman, A.; van Meeteren, N. Preoperative therapeutic programme for elderly patients scheduled for elective abdominal oncological surgery: A randomized controlled pilot study. Clin. Rehabil. 2010, 24, 614-622. [CrossRef] [PubMed]

44. Picorelli, A.M.A.; Pereira, L.S.M.; Pereira, D.S.; Felício, D.; Sherrington, C. Adherence to exercise programs for older people is influenced by program characteristics and personal factors: A systematic review. J. Physiother. 2014, 60, 151-156. [CrossRef]

45. Nederlandse Zorgautoriteit. Toezichtkader Zorgplicht Zorgverzekeraar Zvw-TH/BR-018. 2014. Available online: https://puc.overheid. nl/doc/PUC_21832_22/1 (accessed on 20 May 2021).

46. Dekker, J.W. Indicatorenset. DCRA Verslagjaar. Zorginzicht.nl: Zorginstituut Nederland. 2020. Available online: https:// www.zorginzicht.nl/binaries/content/assets/zorginzicht/kwaliteitsinstrumenten/Indicatorgids+Colorectaal+ carcinoom+\%28DCRA\%29+verslagjaar+2020.pdf (accessed on 20 May 2021).

47. Molenaar, C.J.L.; Janssen, L.; van der Peet, D.L.; Winter, D.C.; Roumen, R.M.H.; Slooter, G.D. Conflicting Guidelines: A Systematic Review on the Proper Interval for Colorectal Cancer Treatment. World J. Surg. 2021, 45, 2235-2250. [CrossRef] [PubMed]

48. Darmon, P.; Karsegard, V.L.; Nardo, P.; Dupertuis, Y.M.; Pichard, C. Oral nutritional supplements and taste preferences: 545 days of clinical testing in malnourished in-patients. Clin. Nutr. 2008, 27, 660-665. [CrossRef] [PubMed]

49. Bohannon, R.W. Minimal clinically important difference for grip strength: A systematic review. J. Phys. Ther. Sci. 2019, 31, 75-78. [CrossRef]

50. Kim, J.; Park, M.; Shin, S. What is the Minimum Clinically Important Difference in Grip Strength? Clin. Orthop. Relat. Res. 2014, 472, 2536-2541. [CrossRef]

51. Barberan-Garcia, A.; Ubré, M.; Roca, J.; Lacy, A.; Burgos, F.; Risco, R.; Momblán, D.; Balust, J.; Blanco, I.; Martínez-Pallí, G. Personalised Prehabilitation in High-risk Patients Undergoing Elective Major Abdominal Surgery: A Randomized Blinded Controlled Trial. Ann. Surg. 2018, 267, 50-56. [CrossRef] [PubMed]

52. Liu, Z.; Qiu, T.; Pei, L.; Zhang, Y.; Xu, L.; Cui, Y.; Liang, N.; Li, S.; Chen, W.; Huang, Y. Two-Week Multimodal Prehabilitation Program Improves Perioperative Functional Capability in Patients Undergoing Thoracoscopic Lobectomy for Lung Cancer: A Randomized Controlled Trial. Anesth. Analg. 2020, 131, 840-849. [CrossRef]

53. Berkel, A.E.M.; Bongers, B.C.; Kotte, H.; Weltevreden, P.; de Jongh Frans, H.C.; Eijsvogel, M.M.M.; Wymenga, A.N.M.; Bigirwamungu-Bargeman, M.; van der Palen, J.; van Det, M.J.; et al. Effects of Community-based Exercise Prehabilitation for Patients Scheduled for Colorectal Surgery With High Risk for Postoperative Complications. Ann. Surg. 2021. [CrossRef] [PubMed] 